\title{
Synthesis of 3-aminocoumarin-N-benzylpyridinium conjugates with nanomolar inhibitory activity against acetylcholinesterase
}

\author{
Nisachon Khunnawutmanotham ${ }^{1}$, Cherdchai Laongthipparos ${ }^{2}$, \\ Patchreenart Saparpakorn ${ }^{3}$, Nitirat Chimnoi ${ }^{4}$ and Supanna Techasakul ${ }^{* 1}$
}

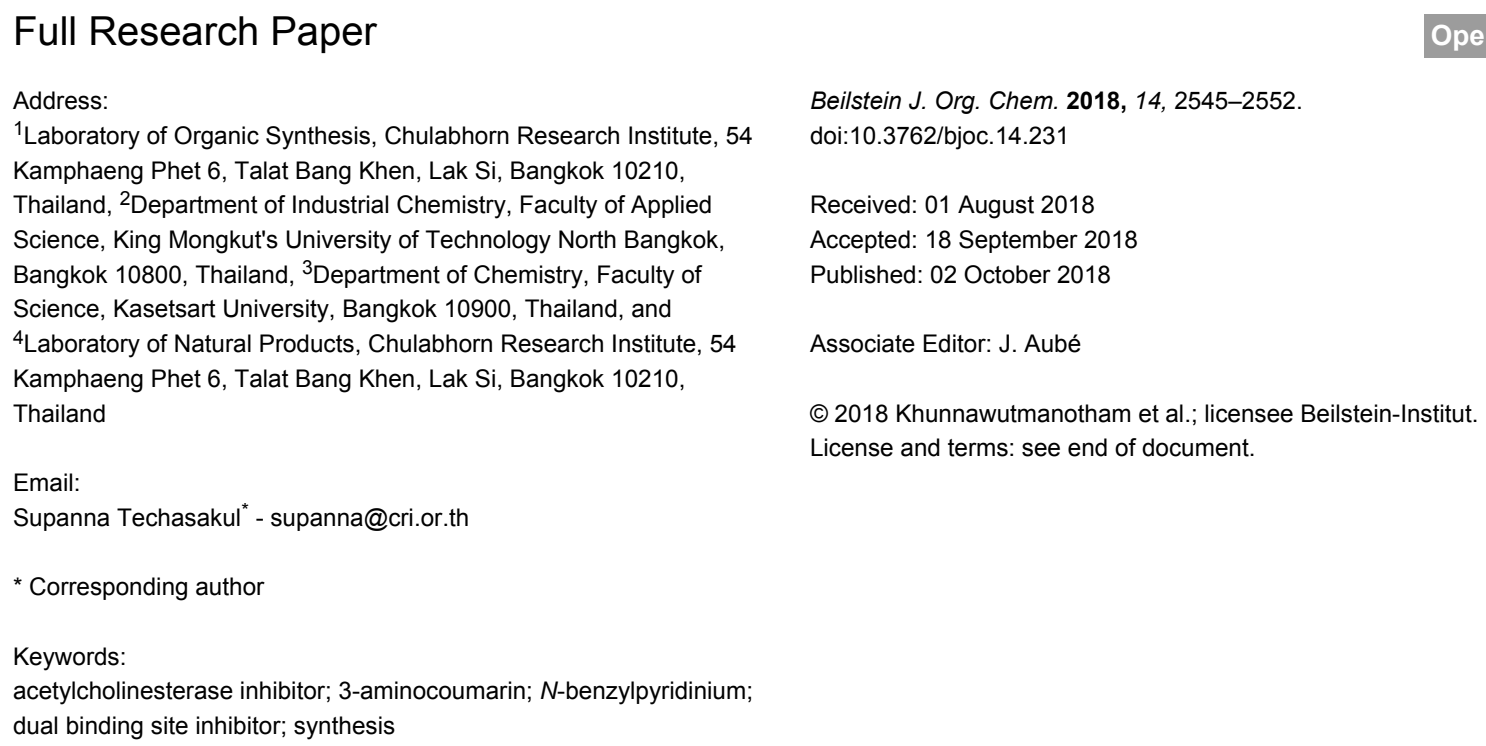

\begin{abstract}
A series of 3-amino-6,7-dimethoxycoumarins conjugated with the $N$-benzylpyridinium moiety through an amide-bond linkage was synthesized and evaluated for their acetylcholinesterase inhibitory activity. A number of the benzylpyridinium derivatives exhibited potent activities with inhibitory concentration $\left(\mathrm{IC}_{50}\right)$ values in the nanomolar concentration range. Among them, the 2,3-difluorobenzylpyridinium-containing compound was the most potent inhibitor with an $\mathrm{IC}_{50}$ value of $1.53 \pm 0.01 \mathrm{nM}$. Docking studies revealed that the synthesized compounds inhibit the target enzyme by a dual binding site mechanism whereby the coumarin portion binds with the peripheral anionic site while the $N$-benzylpyridinium residue binds with the catalytic anionic site of the enzyme.
\end{abstract}

\section{Introduction}

An increasing number of countries are facing a rapid growth of the elderly population. The birth rates of many countries, such as China, Japan, and Thailand are lower than the number theo- 
pected to more than double by 2050 , increasing from 962 million globally in 2017 to 2.1 billion in 2050, and exceed the number of younger people. As people age, they become susceptible to ageing-related health issues, such as arthritis, heart disease, cancer, diabetes and Alzheimer's disease, all of which can potentially decrease the quality of life. Dementia, commonly found among the elderly, can be caused by the Alzheimer's disease (AD) - a progressive neurodegenerative disorder. The Alzheimer's Association reported that one in nine people over the age of 65 suffers from AD [2]. According to this report, approximately 46.8 million people worldwide lived with dementia in 2015, and this number is predicted to reach 75 million in 2030 and 131.5 million in 2050 . AD is a chronic condition that remains incurable; most of the existing treatments only delay the onset or further advancement of AD.

Among the current hypotheses for the treatment of $\mathrm{AD}$, inhibition of acetylcholinesterase enzyme (AChE), which is responsible for the degradation of the neurotransmitter acetylcholine $(\mathrm{ACh})$, is the most widely accepted hypothesis. AChE inhibition can increase ACh levels in the synaptic clefts and then alleviate the cognitive deficit in AD patients. The design of novel acetylcholinesterase inhibitors (AChEIs) has been mostly based on a dual-binding site strategy whereby the designed molecules simultaneously bind to amino acid residues present in both the catalytic anionic site (CAS) and the peripheral anionic site (PAS) of AChE. The CAS is located deeply inside the narrow gorge and is responsible for ACh hydrolysis. On the other hand the PAS is located around the entrance of the active site gorge and is responsible for transient substrate binding before reaching the active site. Especially PAS plays a crucial role in $\beta$-amyloid $(\mathrm{A} \beta$ ) fibrillogenesis in $\mathrm{AD}$ patients by forming stable AChE-A $\beta$ complexes $[3,4]$. Thus, these types of effects may render them potential therapeutic agents for AD treatment. Hybrid compounds such as huperzine A-tacrine hybrids [5], donepezil-tacrine hybrid related derivatives [6,7] and tacrine-indole hybrids [8] with dual-binding site properties exhibit potent $\mathrm{AChE}$ inhibition activities. In addition, coumarin compounds linked with various side chain moieties [9-11] as well as with benzylpyridinium moieties [12-14] have been reported as dual-binding site AChE inhibitors. Recently we have reported the AChE inhibitory activity of the coumarin derivative, scopoletin conjugated with a pyridinium side chain (Figure 1) [15] and a docking study revealed that the scopoletin portion of the compound binds to amino acid residues in PAS, whereas the $N$-benzylpyridinium moiety binds to those present in the CAS of AChE. To develop potent AChE inhibitors, we were interested in aminocoumarin as a replacement of scopoletin due to the presence of the amino group in the former that may be useful for binding with this enzyme. Herein, we report our progress on the synthesis, biological evaluation, and molec- ular docking of 3-aminocoumarin linked with the benzylpyridinium moiety through an amide bond.

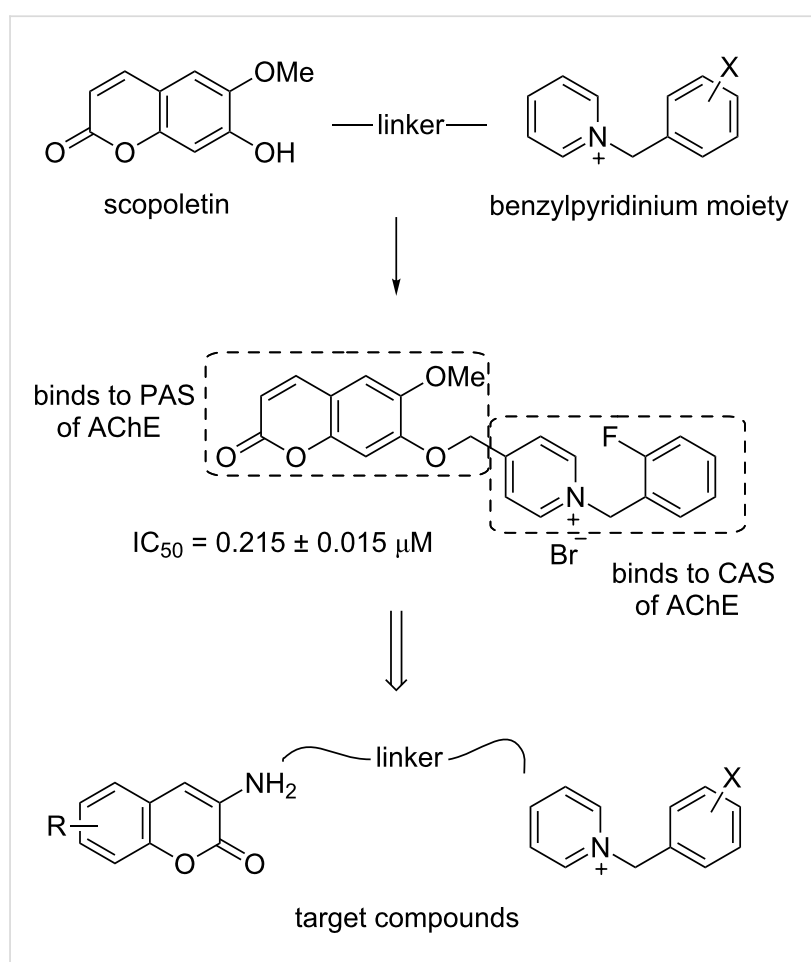

Figure 1: Design of the target compounds.

\section{Results and Discussion Chemistry}

The target 3-aminocoumarin- $N$-benzylpyridinium compounds 4a, 5a, 9a-9i, and 10a were synthesized as shown in Scheme 1. 3-Acetamidocoumarin (2) was prepared following Dakin's procedure [16] by reacting salicylaldehyde (1) with $\mathrm{N}$-acetylglycine in acetic anhydride at $110{ }^{\circ} \mathrm{C}$ for $7 \mathrm{~h}$. Hydrolysis of 2 with $50 \% \mathrm{HCl}$ in ethanol at $100{ }^{\circ} \mathrm{C}$ for $1 \mathrm{~h}$ provided 3 -aminocoumarin (3). Treatment of $\mathbf{3}$ with either isonicotinyl chloride $(n=0)$ or 4-pyridylacetyl chloride $(n=1)$, generated by reacting the corresponding carboxylic acid with oxalyl chloride, in the presence of triethylamine provided the $\mathrm{N}$-acyl-3aminocoumarins 4 or 5, respectively. The analogs 9 and 10, which contain dimethoxy substituents on the coumarin ring, were prepared in the same manner, starting from 2-hydroxy-4,5dimethoxybenzaldehyde (6). Finally, the benzylpyridinium bromide salts $4 \mathbf{a}, 5 \mathbf{a}, 9 \mathbf{a}-9 \mathbf{i}$, and $10 \mathbf{a}$ were obtained by treatment of $4,5,9$, and 10 with substituted benzyl bromides in dichloromethane at room temperature for $72 \mathrm{~h}$.

\section{Inhibition of AChE}

The AChE inhibitory activity of the synthesized compounds was evaluated by Ellman's method [17] using Electrophorus electricus AChE; donepezil hydrochloride and tacrine were 


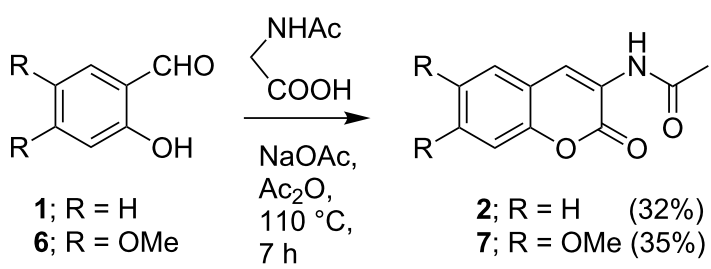

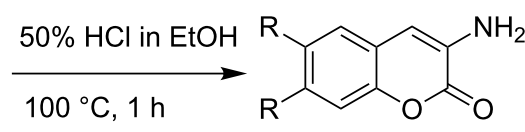

$3 ; \mathrm{R}=\mathrm{H} \quad(89 \%)$
$8 ; \mathrm{R}=$ OMe $(48 \%)$
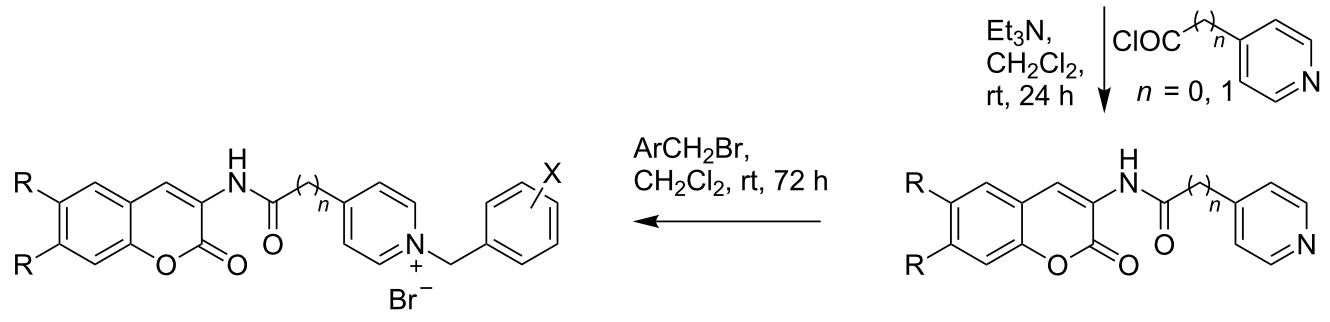

4a; $\mathrm{R}=\mathrm{X}=\mathrm{H}(n=0) \quad 5 \mathrm{a} ; \mathrm{R}=\mathrm{X}=\mathrm{H}(n=1)$

9a-9i; $\mathrm{R}=\mathrm{OMe}(n=0)$ 10a; $\mathrm{R}=\mathrm{OMe}, \mathrm{X}=\mathrm{H}(n=1)$

Scheme 1: Synthesis of 3-aminocoumarin- $N$-benzylpyridinium salts.

used as the reference compounds. The tested compounds with more than $50 \%$ enzyme inhibition at a concentration of $1 \mu \mathrm{M}$ were further evaluated for their half maximal inhibitory concentration $\left(\mathrm{IC}_{50}\right)$ values, and the results are shown in Table 1.

3-Aminocoumarins $\mathbf{3}$ and $\mathbf{8}$ were found to be inactive and did not inhibit AChE activity ( $12 \%$ and $5 \%$ at $1 \mu \mathrm{M}$, respectively). Also, their conversion to $N$-acyl-3-aminocoumarins 4, 5, 9, and $\mathbf{1 0}$ did not lead to any improvement (\% inhibitions of all compounds were less than $10 \%$ at $1 \mu \mathrm{M}$ ). In order to screen the AChE inhibitory activities of the pyridinium salts, compounds $4,5,9$, and 10 were treated with benzyl bromide to provide the corresponding $N$-benzylpyridinium salts $4 \mathbf{a}, \mathbf{5 a}, 9 \mathbf{9}$, and 10a, respectively. The conversion of $\mathbf{4}$ to $\mathbf{4 a}$ resulted in an increased AChE inhibitory activity (from inactive to an $\mathrm{IC}_{50}$ of $71.88 \pm 3.40 \mathrm{nM}$ ). On the other hand, the corresponding $\mathrm{N}$-benzylpyridinium salt of $\mathbf{5}$ (compound 5a) displayed only poor activity, which was comparable to that of its parent compound $(10 \%$ inhibition at concentration of $1 \mu \mathrm{M})$. A comparison of the $\mathrm{IC}_{50}$ values of $\mathbf{4 a}$ and $\mathbf{5 a}$ indicated that the presence of a methylene unit between the carbonyl group and the pyridine moiety lowered the inhibitory potency. This hypothesis was confirmed when comparing the AChE inhibitory activity of 9a with that of 10a. The $N$-benzylpyridinium salt 9a, lacking the aforementioned methylene group possessed an $\mathrm{IC}_{50}$ value against $\mathrm{AChE}$ of $12.48 \pm 0.71 \mathrm{nM}$, whereas the $N$-benzylpyridinium salt 10a, obtained from 10, had an $\mathrm{IC}_{50}$ value of $1087.7 \pm 0.05 \mathrm{nM}$. Based on these findings, the coumarin isonicotinamides 4 or 9 were selected as appropriate precursors for the preparation of the subsequent pyridinium salts. The pres- ence of methoxy groups in the 6 and 7 positions of the coumarin ring remarkably enhanced the inhibitory activity against AChE as observed from the comparisons of compounds $9 \mathbf{a}\left(\mathrm{IC}_{50}\right.$ of $12.48 \pm 0.71 \mathrm{nM})$ and $4 \mathbf{a}\left(\mathrm{IC}_{50}\right.$ of $\left.71.88 \pm 3.44 \mathrm{nM}\right)$, and of compounds 10a $\left(\mathrm{IC}_{50}\right.$ of $\left.1087.7 \pm 0.05 \mathrm{nM}\right)$ and $\mathbf{5 a}(10 \%$ at a concentration of $1 \mu \mathrm{M})$. The results suggested that combining the $N$-benzylpyridinium moiety with the 3-amino-6,7dimethoxycoumarin core through the amide bond provides a significant enhancement of the AChE inhibitory activity. As mentioned above, compound 9 was then selected as the parent core for the synthesis of other substituted benzylpyridinium salts for further evaluation of their AChE inhibitory activity.

On the basis of the potent activity of 9a $\left(\mathrm{IC}_{50}\right.$ of $12.48 \pm 0.71 \mathrm{nM}$ ), further modifications by introducing chlorine or fluorine substituents at the ortho-, meta-, or para-positions on the benzyl group were investigated. The results showed that the type and the position of the substituents on the benzyl group influenced the inhibitory activity against AChE. For chlorine as a substituent, the activity followed the order of ortho $>$ meta $>$ para. Compared with benzylpyridinium salt 9a, a chlorine substitution at the $o$-position $(9 \mathbf{b})$ provided a two-fold improvement in activity, whereas $m$ - and $p$-substitutions $(\mathbf{9 c}$ and 9d, respectively) led to comparable and diminished inhibitory activities, respectively. For fluorine as a substituent, the activity also followed the order of ortho $>$ meta $\approx$ para. The AChE inhibitory activities of all fluorine analogs were superior to those of the chlorine analogs and the unsubstituted benzylpyridinium salt 9a. In detail, a fluorine substituent at the ortho-position $(9 e)$ increased the inhibitory activity with an $\mathrm{IC}_{50}$ value of 


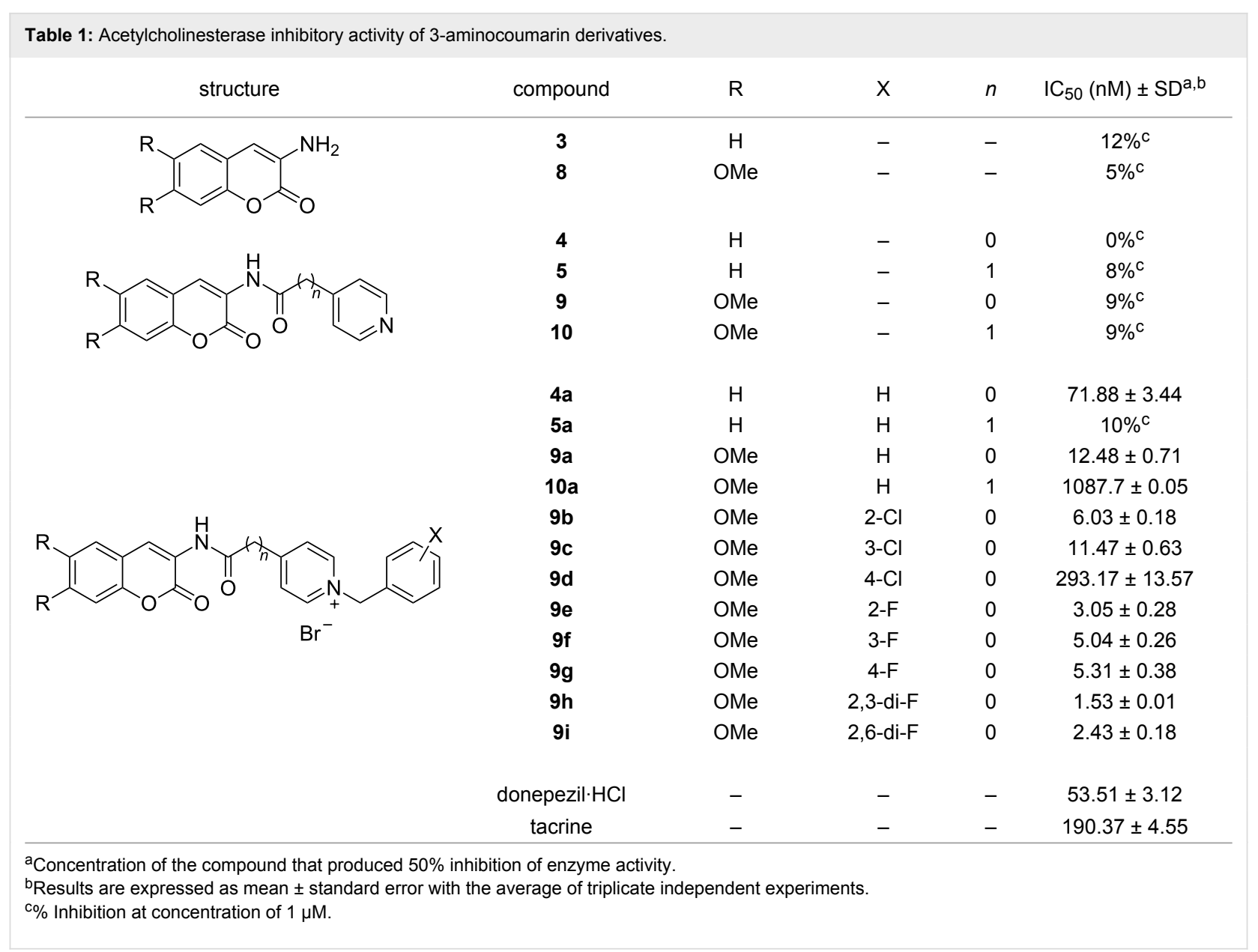

$3.05 \pm 0.28 \mathrm{nM}$, whereas the $m$ - and $p$-fluoro-substituted analogs $9 f$ and $9 \mathrm{~g}$ provided comparable $\mathrm{IC}_{50}$ values of $5.04 \pm 0.26$ and $5.31 \pm 0.38 \mathrm{nM}$, respectively. Difluorinated benzylpyridinium salts were also examined for their inhibitory activities and were found to be more active than the corresponding monofluorinated compounds. Thus compound $\mathbf{9 h}$, a 2,3difluorobenzylpyridinium salt, exhibited the highest activity in this study with an $\mathrm{IC}_{50}$ value of $1.53 \pm 0.01 \mathrm{nM}$ and compound 9i having a 2,6-difluorobenzyl substituent showed a slightly inferior activity with an $\mathrm{IC}_{50}$ value of $2.43 \pm 0.18 \mathrm{nM}$. The $\mathrm{IC}_{50}$ value of $\mathbf{9 h}$, the most active compound in this study, was 35 -fold lower than that of donepezil hydrochloride ( $\mathrm{IC}_{50}$ of $53.51 \pm 3.12 \mathrm{nM}$ ) and 124 -fold lower than that of tacrine $\left(\mathrm{IC}_{50}\right.$ of $\left.190.37 \pm 4.55 \mathrm{nM}\right)$. Moreover, $9 \mathrm{~h}$ was inactive against MRC-5 normal embryonic lung cell $(0 \%$ cytotoxicity at concentration of $50 \mu \mathrm{g} / \mathrm{mL}$ ).

\section{Molecular docking studies}

Molecular docking studies [15] were performed to study the binding mode and interactions of the synthesized compounds with AChE. A crystal structure of recombinant human acetyl- cholinesterase complexed with donepezil (PDB code 4ey7) [18] retrieved from the Protein Data Bank was used in the study because of its high similarity (approximately $88 \%$ similarity), good resolution (at $2.35 \AA$ ) and ligand state with donepezil of Human AChE structure. Molecular docking of AChE via the GOLD v5.2.2 program [19] was used to investigate the orientation of the compounds in the rhAChE binding site. Compounds 4a, 9a, 9b, 9e, 9h, 9i, and 10 a were selected as representatives for the docking study.

The active site of human AChE, which is at the bottom of a deep and narrow gorge, consists of several major domains. A catalytic triad (CT) that comprises Ser203, His447, and Glu334 residues is responsible for hydrolyzing the ester bond of $\mathrm{ACh}$ [20]. The CAS, which is responsible for the binding of the quaternary ammonium moiety of choline, consists of Trp86, Tyr133, Tyr337, and Phe338 [21]. The acyl pocket, which binds to the acetyl group of ACh, consists of Phe295 and Phe297 residues [21]. The oxyanion hole that interacts with the ACh carbonyl oxygen consists of Gly121, Gly122, and Ala204 $[22,23]$. In addition to the active site another binding site, 
known as PAS, is located around the entrance of the active site gorge. The PAS consists of Tyr72, Asp74, Tyr124, Trp286, and Tyr341 [23,24].

From the docking result, the docked orientation of donepezil showed a root-mean-square deviation (RMSD) of $0.474 \AA$ when compared with the conformation in the crystal structure, thereby indicating its potential as a suitable method for the binding mode of compounds in the rhAChE binding site. The docked conformations of donepezil and the synthesized compounds are shown in Figure 2. All docked compounds were located similar to donepezil in the binding pocket. The benzylpyridinium moiety was bound close to the CT and the CAS while the chromene rings were located at the PAS. Compounds 9a, 9b, $\mathbf{9 e}, 9 \mathbf{h}$, and $9 \mathbf{i}$ revealed similar orientations in the binding pocket whereas the binding of compounds $4 \mathbf{a}$ and $10 \mathbf{a}$ was partially different. The orientation of the chromene ring of compound 4a was shifted away from the others, whereas the chromene ring of compound 10a was flipped to the opposite site when compared with the other compounds.

The binding interactions of each compound are shown in Figure 3. The most active compound $\mathbf{9 h}$ (Figure 3e) formed H-bond interactions to the residues in the following binding sites: (1) the methylene unit of the benzyl group to the CT amino acid residue His447; (2) the carbonyl of the amide moiety and fluorine atoms to the amino acid residues Trp86, Tyr337, and Phe338 in the CAS; (3) the carbonyl group of the chromene ring to the acyl pocket amino acid residue Phe295; (4) the nitrogen atom of the amide group and dimethoxy substituents on the chromene ring to the amino acid residues Tyr72,
Tyr124, Trp286, and Tyr341 in the PAS; and (5) the hydrogen atoms of phenyl ring to Glu202 and a methoxy group to Ser293. Moreover, $\mathrm{C}-\mathrm{H}-\pi$ and $\pi-\pi$ interactions were found for compound $9 \mathbf{h}$. The $\mathrm{C}-\mathrm{H}-\pi$ interactions were found between hydrogen atoms of the methoxy group to the PAS amino acid residue Tyr72 and the pyridinium ring to the CAS amino acid residue Phe338, whereas $\pi-\pi$ interactions were found among the chromene ring, pyridinium, and phenyl ring to Trp286, Phe338, and Trp86, respectively. When the position of the fluoro-substituent(s) of $9 \mathbf{h}$ was changed or removed, the inhibitory activity decreased, as observed in the cases of compounds $9 \mathbf{e}$ (Figure 3d) and 9i (Figure 3f). From the docked conformation of compounds $9 \mathbf{e}$ and $9 \mathbf{i}$, the absence of the 3-fluoro-substituent caused a loss of the H-bond interaction to Trp86 in the CAS. Their conformations were slightly shifted up from Trp86 to form stronger a H-bond interaction between the 2-fluoro-substituent and a hydrogen atom of the $\beta$-carbon, thereby causing the slight shift of the remaining parts of the structures. For instance, the methoxy group of the chromene ring moved away from Tyr72 in the PAS; thus, compounds $9 e$ and $9 \mathbf{i}$ lost $\mathrm{H}$-bond interactions to Tyr72. Moreover, the $\mathrm{C}-\mathrm{H}-\pi$ interactions of compounds $9 \mathrm{e}$ and $9 \mathbf{i}$ to Tyr72 became weaker. All other $\mathrm{H}$-bonds, $\mathrm{C}-\mathrm{H}-\pi$ and $\pi-\pi$ interactions of $9 \mathbf{e}$ and $\mathbf{9 i}$ to amino acid residues in the binding site were similar to those found in compound $9 \mathrm{~h}$. When comparing the interaction between compounds $9 \mathrm{e}$ and $\mathbf{9 i}$, the 6-fluoro-substituent in compound $9 \mathbf{i}$ can form a stronger H-bond interaction to His447. The absence of the 6-fluoro-substituent also caused a slight shift of the methoxy position on the chromene ring away from Tyr72. Therefore, this phenomenon can be a reason for the inferior activity of compound $9 \mathrm{e}$ when compared with compound $\mathbf{9 i}$. For com- 


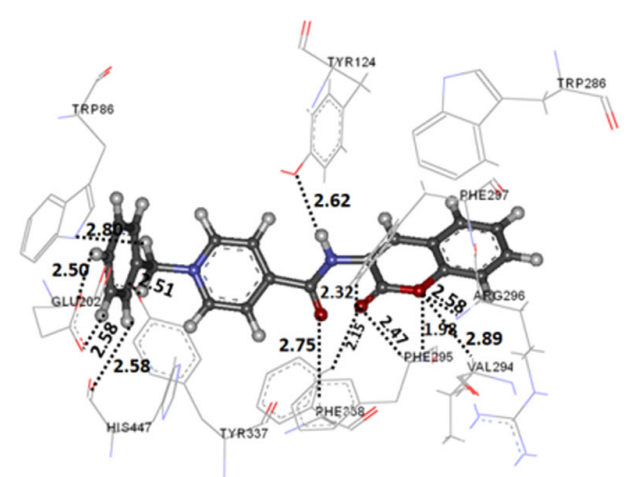

(a) Compound 4a

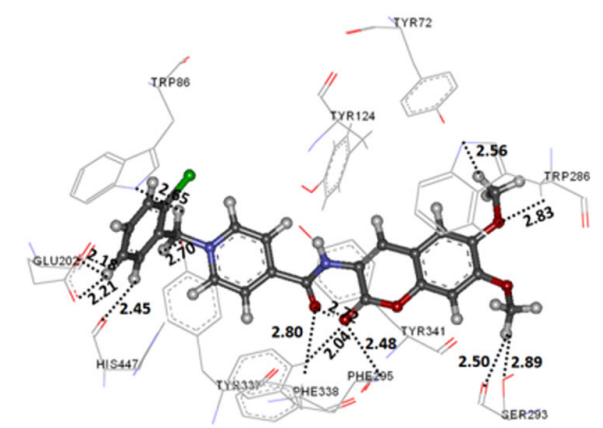

(c) Compound 9b

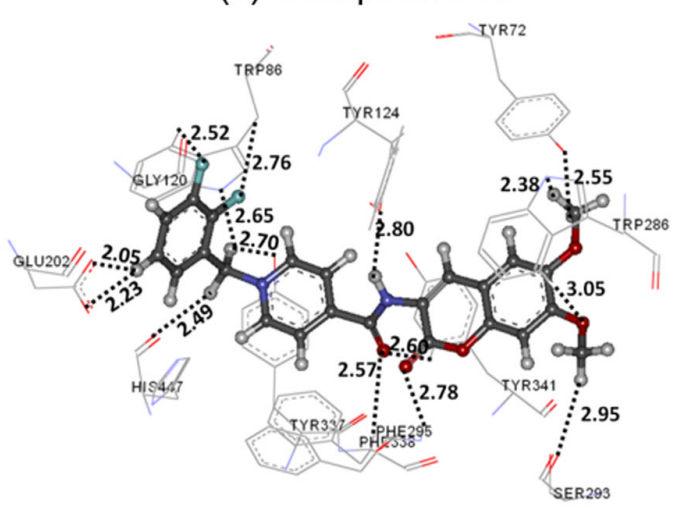

(e) Compound 9h

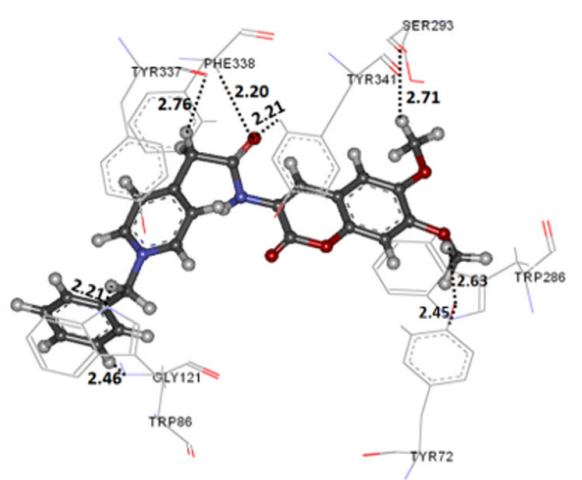

(g) Compound 10a

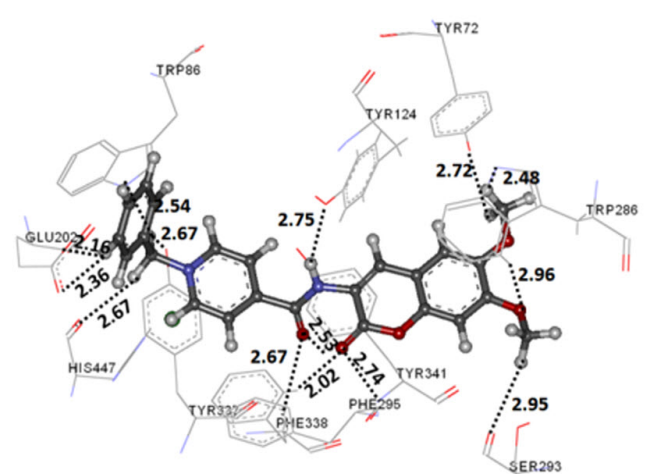

(b) Compound 9a

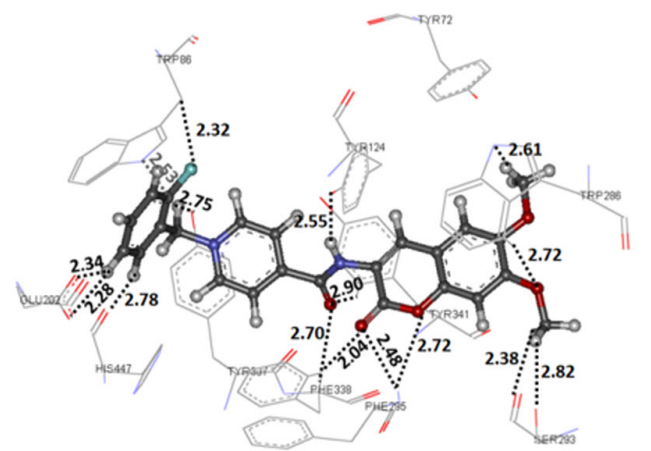

(d) Compound 9e

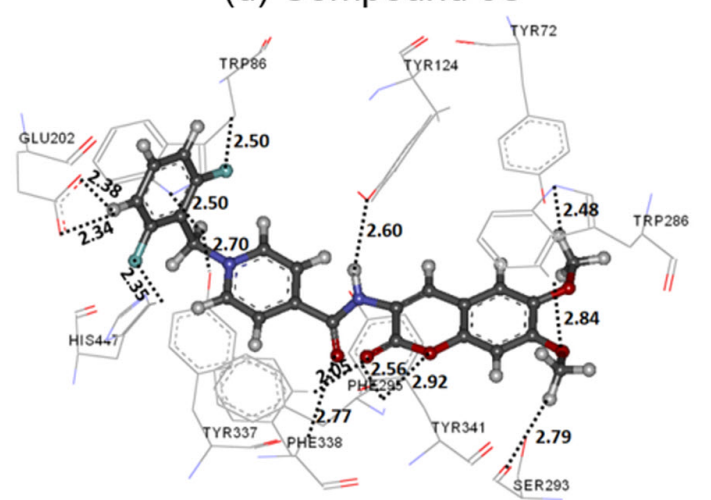

(f) Compound 9i

Figure 3: Binding interactions in the rhAChE binding pocket with (a) $4 a$, (b) $9 a$, (c) $9 b$, (d) $9 e,(e) 9 h$, (f) $9 i$, and (g) 10a. Distances are shown in angstrom $(\AA)$. 
pound $9 \mathbf{b}$ (Figure 3c), the presence of a bulkier chlorine substituent at the $o$-position of the phenyl ring resulted in the shift of the phenyl ring away from Trp86, as well as shifting of other parts. These shifts led to slightly weaker $\mathrm{C}-\mathrm{H}-\pi$ and $\pi-\pi$ interactions between compound $\mathbf{9 b}$ and Tyr72, Trp86, Tyr337, and Phe338. In case of compound 9a (Figure 3b), the docked conformation was aligned similar to the conformation of compound $9 \mathbf{h}$. However, because of the absence of fluoro-substituents, compound 9a does not form a H-bond interaction to Trp86, which explains the lower activity of compound 9a compared with compound $\mathbf{9 h}$. For compounds $\mathbf{4 a}$ (Figure $3 \mathrm{a}$ ) and 10a (Figure 3g), the docked conformations were partially different from the other compounds. In the case of $\mathbf{4 a}$, having no methoxy substituents on the chromene ring, no H-bonds and $\mathrm{C}-\mathrm{H}-\pi$ interactions to Tyr72, Trp286, and Tyr341 are observed. In compound $\mathbf{1 0 a}$, one additional methylene group between the pyridinium and the carbonyl groups caused the chromene ring to flip in the binding pocket. The other parts of the structure also shifted when compared with the other compounds. Compared with compound $\mathbf{9 h}$, these shifts of docked compound 10a led to the loss of $\mathrm{H}$-bonds, as well as $\mathrm{C}-\mathrm{H}-\pi$ and $\pi-\pi$ interactions with $\mathrm{AChE}$, thereby reducing the inhibitory activity.

The docking study showed that the docked orientations of the selected compounds in the binding pocket were similar to that of donepezil. The results indicated binding interactions between the chromene ring and the PAS amino acids residues as well as between the benzylpyridinium moiety and the CAS amino acid residues. Interactions between the carbonyl groups of the chromene ring and of the amide group to Phe338 in the CAS and between the nitrogen atom of the amide group to Tyr124 in the PAS were the key interactions of the synthesized 3 -aminocoumarin- $N$-benzylpyridinium conjugates in the binding pocket of AChE.

\section{Conclusion}

A series of 3-amino-6,7-dimethoxycoumarins conjugated with the $N$-benzylpyridinium moiety through an amide linkage was synthesized and investigated for their AChE inhibitory activities. A number of benzylpyridinium derivatives exhibited potent activity with $\mathrm{IC}_{50}$ values in the nanomolar concentration range. The results showed that the dimethoxy substituent on the chromene ring, the length of the amide linker, as well as the type and position of substituents on the benzyl group all contributed significantly to the AChE inhibitory activity. The 6,7dimethoxy-substituted chromene ring significantly enhances the activity. An additional methylene unit of the linker between the amide carbonyl group and the pyridine ring led to a diminished activity. The fluorine substituent at the ortho-position on the benzyl ring provided a remarkable increase in $\mathrm{AChE}$ inhibition. Among the derivatives, the 2,3-difluorobenzylpyridinium compound was the most potent with an $\mathrm{IC}_{50}$ value of $1.53 \pm 0.01 \mathrm{nM}$, followed by the 2,6-difluorobenzylpyridinium and 2-fluorobenzylpyridinium analogs with $\mathrm{IC}_{50}$ values of $2.43 \pm 0.18$ and $3.05 \pm 0.28 \mathrm{nM}$, respectively. Docking studies revealed that the synthesized compounds can act as dual binding site inhibitors by allowing the coumarin portion to bind with the PAS and the $N$-benzylpyridinium residue to bind with the CAS of AChE.

\section{Supporting Information}

\section{Supporting Information File 1}

Experimental details, characterization data and copies of NMR spectra.

[https://www.beilstein-journals.org/bjoc/content/ supplementary/1860-5397-14-231-S1.pdf]

\section{Acknowledgements}

We gratefully acknowledge Dr. Poonsakdi Ploypradith at the Chulabhorn Research Institute for a critical reading of the manuscript. We also thank Miss Kittiporn Trisupphakant for recording EIMS and IR spectral data.

\section{ORCID ${ }^{\circledR} i \mathrm{iDs}$}

Supanna Techasakul - https://orcid.org/0000-0002-6540-5362

\section{References}

1. United Nations, Department of Economic and Social Affairs, Population Division. World Population Prospects: The 2017 Revision; United Nations: New York, 2017.

2. Prince, M.; Comas-Herrera, A.; Knapp, M.; Guerchet, M.; Karagiannidou, M. World Alzheimer Report 2016. Improving healthcare for people living with dementia. Coverage, quality and cost now and in the future; Alzheimer's Disease International: London, 2016.

3. Inestrosa, N. C.; Alvarez, A.; Pérez, C. A.; Moreno, R. D.; Vicente, M.; Linker, C.; Casanueva, O. I.; Soto, C.; Garrido, J. Neuron 1996, 16, 881-891. doi:10.1016/S0896-6273(00)80108-7

4. Alvarez, A.; Opazo, C.; Alarcón, R.; Garrido, J.; Inestrosa, N. C. J. Mol. Biol. 1997, 272, 348-361. doi:10.1006/jmbi.1997.1245

5. Gemma, S.; Gabellieri, E.; Huleatt, P.; Fattorusso, C.; Borriello, M.; Catalanotti, B.; Butini, S.; De Angelis, M.; Novellino, E.; Nacci, V.; Belinskaya, T.; Saxena, A.; Campiani, G. J. Med. Chem. 2006, 49, 3421-3425. doi:10.1021/jm060257t

6. Camps, P.; Formosa, X.; Galdeano, C.; Gómez, T.; Muñoz-Torrero, D.; Ramírez, L.; Viayna, E.; Gómez, E.; Isambert, N.; Lavilla, R.; Badia, A.; Clos, M. V.; Bartolini, M.; Mancini, F.; Andrisano, V.; Bidon-Chanal, A.; Huertas, Ó.; Dafni, T.; Luque, F. J. Chem.-Biol. Interact. 2010, 187, 411-415. doi:10.1016/j.cbi.2010.02.013

7. Alonso, D.; Dorronsoro, I.; Rubio, L.; Muñoz, P.; García-Palomero, E.; Del Monte, M.; Bidon-Chanal, A.; Orozco, M.; Luque, F. J.; Castro, A.; Medina, M.; Martínez, A. Bioorg. Med. Chem. 2005, 13, 6588-6597. doi:10.1016/j.bmc.2005.09.029 
8. Muñoz-Ruiz, P.; Rubio, L.; García-Palomero, E.; Dorronsoro, I.; del Monte-Millán, M.; Valenzuela, R.; Usán, P.; de Austria, C.; Bartolini, M.; Andrisano, V.; Bidon-Chanal, A.; Orozco, M.; Luque, F. J.; Medina, M.; Martínez, A. J. Med. Chem. 2005, 48, 7223-7233. doi:10.1021/jm0503289

9. Catto, M.; Pisani, L.; Leonetti, F.; Nicolotti, O.; Pesce, P.; Stefanachi, A.; Cellamare, S.; Carotti, A. Bioorg. Med. Chem. 2013, 21 , 146-152. doi:10.1016/j.bmc.2012.10.045

10. Asadipour, A.; Alipour, M.; Jafari, M.; Khoobi, M.; Emami, S.; Nadri, H.; Sakhteman, A.; Moradi, A.; Sheibani, V.; Moghadam, F. H.; Shafiee, A.; Foroumadi, A. Eur. J. Med. Chem. 2013, 70, 623-630. doi:10.1016/j.ejmech.2013.10.024

11. Ghanei-Nasab, S.; Khoobi, M.; Hadizadeh, F.; Marjani, A.; Moradi, A.; Nadri, H.; Emami, S.; Foroumadi, A.; Shafiee, A. Eur. J. Med. Chem. 2016, 121, 40-46. doi:10.1016/j.ejmech.2016.05.014

12. Vafadarnejad, F.; Mahdavi, M.; Karimpour-Razkenari, E.; Edraki, N.; Sameem, B.; Khanavi, M.; Saeedi, M.; Akbarzadeh, T. Bioorg. Chem. 2018, 77, 311-319. doi:10.1016/j.bioorg.2018.01.013

13. Alipour, M.; Khoobi, M.; Foroumadi, A.; Nadri, H.; Moradi, A.; Sakhteman, A.; Ghandi, M.; Shafiee, A. Bioorg. Med. Chem. 2012, 20 , 7214-7222. doi:10.1016/j.bmc.2012.08.052

14. Lan, J.-S.; Ding, Y.; Liu, Y.; Kang, P.; Hou, J.-W.; Zhang, X.-Y.; Xie, S.-S.; Zhang, T. Eur. J. Med. Chem. 2017, 139, 48-59. doi:10.1016/j.ejmech.2017.07.055

15. Khunnawutmanotham, N.; Chimnoi, N.; Saparpakorn, P.; Techasakul, S. Bioorg. Chem. 2016, 65, 137-145. doi:10.1016/j.bioorg.2015.12.002

16. Dakin, H. D. J. Biol. Chem. 1929, 82, 439-446.

17. Ellman, G. L.; Courtney, K. D.; Andres, V., Jr.; Featherstone, R. M. Biochem. Pharmacol. 1961, 7, 88-95. doi:10.1016/0006-2952(61)90145-9

18. Cheung, J.; Rudolph, M. J.; Burshteyn, F.; Cassidy, M. S.; Gary, E. N.; Love, J.; Franklin, M. C.; Height, J. J. J. Med. Chem. 2012, 55, 10282-10286. doi:10.1021/jm300871x

19. Jones, G.; Willett, P.; Glen, R. C.; Leach, A. R.; Taylor, R. J. Mol. Biol. 1997, 267, 727-748. doi:10.1006/jmbi.1996.0897

20. Shafferman, A.; Kronman, C.; Flashner, Y.; Leitner, M.; Grosfeld, H.; Ordentlich, A.; Gazes, Y.; Cohen, S.; Ariel, N.; Barak, D. J. Biol. Chem. 1992, 267, 17640-17648.

21. Ordentlich, A.; Barak, D.; Kronman, C.; Flashner, Y.; Leitner, M.; Segall, Y.; Ariel, N.; Cohen, S.; Velan, B.; Shafferman, A. J. Biol. Chem. 1993, 268, 17083-17095.

22. Sussman, J. L.; Harel, M.; Frolow, F.; Oefner, C.; Goldman, A.; Toker, L.; Silman, I. Science 1991, 253, 872-879. doi:10.1126/science.1678899

23. Johnson, G.; Moore, S. W. Curr. Pharm. Des. 2006, 12, 217-225. doi:10.2174/138161206775193127

24. Bourne, Y.; Taylor, P.; Radić, Z.; Marchot, P. EMBO J. 2003, 22, 1-12. doi:10.1093/emboj/cdg005

\section{License and Terms}

This is an Open Access article under the terms of the Creative Commons Attribution License (http://creativecommons.org/licenses/by/4.0). Please note that the reuse, redistribution and reproduction in particular requires that the authors and source are credited.

The license is subject to the Beilstein Journal of Organic Chemistry terms and conditions:

(https://www.beilstein-journals.org/bjoc)

The definitive version of this article is the electronic one which can be found at:

$\underline{\text { doi:10.3762/bjoc. } 14.231}$ 